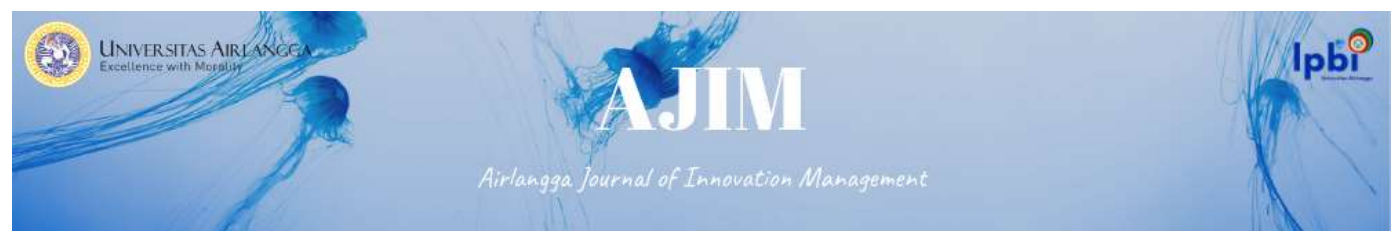

Vol.1 No.1 June 2020

e-ISSN: 2722-5062

DOI: 10.20473/ajim.v1i1.19376

\title{
PEMANFAATAN APRS (AUTOMATIC POSITION REPORTING SYSTEM ) BERBASIS IOT (INTERNET Of THINGS) SEBAGAI MEDIA PENGAMATAN CUACA
}

\author{
Fiqih Ismawan', Muhamad Irsan ${ }^{2}$ \\ ${ }^{1}$ Universitas Indraprasta PGRI \\ Jl. Raya Tengah No. 80, Jakarta Timur 13760 \\ ${ }^{2}$ Universitas Indraprasta PGRI \\ Jl. Raya Tengah No. 80, Jakarta Timur 13760 \\ Corresponding e-mail: atstairway@gmail.com
}

\begin{abstract}
This paper reports on the potential use of Automatic Packet Reporting System (APRS) technology as weather observations. Observations and measurements made through the process of recording information captured at the APRS data reception station on the aprs.fi site are based on the coordinate points monitored, especially in the Greater Jakarta area. This study aims to have a data package taken at the aprs.fi site reported in real time at each coordinate point believed to be able to be used as information to predict early weather observations based on system requirements. The method will be used by observing and analyzing potential APR system users based on the number and measurement of data by the APRS Internet System (APRS-IS) system on the aprs.fi site. The results showed high reliability on the use of IoT technology in the Automatic PacketReporting System (APRS) as a weather observation, measurement of air humidity, directional pressure can be the current solution.
\end{abstract}

Keywords: APRS; IoT; humidity; weather monitoring;

\begin{abstract}
ABSTRAK
Penelitian ini melaporkan tentang potensi penggunaan teknologi Automatic Packet Reporting System (APRS) sebagai pengamatan cuaca. Pengamatan dan pengukuran yang dilakukan melalui proses perekaman informasi yang ditangkap di stasiun penerimaan data APRS pada situs aprs.fi berdasarkan titik koordinat yang terpantau khususnya di wilayah Jabodetabek. Penelitian ini bertujuan dengan adanya paket data yang diambil pada situs aprs.fi yang dilaporkan secara real time pada tiap titik koordinat diyakini mampu dijadikan informasi untuk memprediksi pengamatan cuaca secara dini berdasarkan kebutuhan sistem. Metode yang akan digunakan dengan melakukan observasi serta menganalisis potensi pengguna sistem aprs berdasarkan jumlah dan pengukuran data oleh sistem APRS Internet System (APRS-IS) pada situs aprs.fi. Hasil penelitian menunjukkan adanya reliabilitas yang tinggi pada penggunaan teknologi IoT pada Automatic PacketReporting System (APRS)sebagai pengamatan cuaca, pengukuran kelembaban udara, tekanan arah mata angin dapat menjadi solusi saat ini..
\end{abstract}




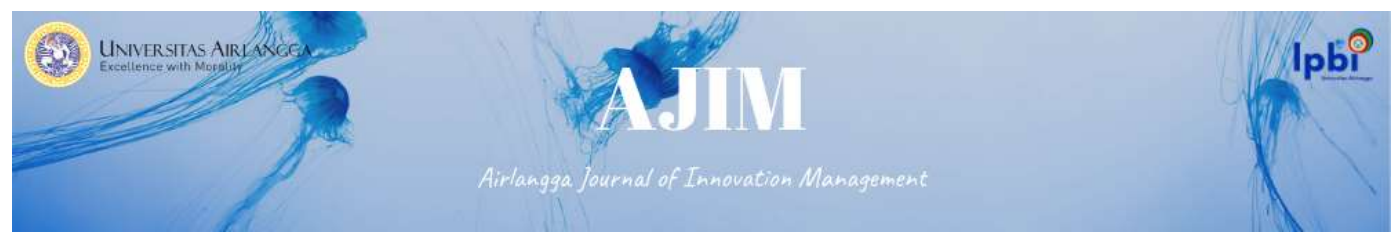

Kata Kunci : APRS; IoT; kelembaban udara; monitoring cuaca;

\section{PENDAHULUAN}

Hujan adalah parameter atmosfer yang memiliki pengaplikasian yang luas baik di bidang hidrologi, sosial, dan berbagai ilmu bumi(Tapiador et al., 2012). Pengetahuan tentang cuaca menjadi faktor penting untuk berbagai keperluan menganalisis fenomena alam yang terjadi seperti kekeringan, banjir, udara, manajemen sumber daya, pertanian dan lainnya. Agar proses dan hasil dari fenomena tersebut dapat tercapai secara maksimal, maka data curah hujan yang digunakan harus tersedia dengan baik, baik temporal (waktu tersedia) dan spasial(Susanti et al., 2020).

Melihat kondisi cuaca dan kelembaban udara saat ini semakin memprihatinkan, cuaca yang kurang kondusif dan tidak dapat di prediksi mengakibatkan sulitnya mengetahui kondisi keadaan cuaca saat ini. Informasi kondisi cuaca dirasakan perlu untuk disebarluaskan guna memberikan informasi kondisi yang terjadi dan yang mungkin akan terjadi. Informasi yang disajikan dapat berupa dampak dari kondisi cuaca tersebut, selain itu juga dapat disertakan jenis-jenis peringatan lainnyayang berkaitan dengan cuaca. Laporan prediksi cuaca sebagai alat ukur tingkat cuaca dan tingkat kelembaban udara tidak luput dari pencarian pengguna informasi untuk mengetahui tingkatan suhu cuaca, persentase kelembaban udara serta tekanan arah angin. Keakuratan laporan informasi yang disajikan dalam memprediksi cuaca menjadi sumber informasi yang harus relevan dengan keadaan secara real time, hadirnya teknologi Automatic PacketReporting System $(A P R S)$ menjadi salah satu alternatif untuk pengamatan cuaca, pengukuran kelembaban udara, tekanan arah angin bahkan kondisi curah hujan.

Automatic PacketReporting System (APRS) dapat menjadi sebuah sarana komunikasi alternatif pada daerah-daerah bencana, terutama jika tidak adanya sinyal dari alat komunikasi berbasis Global System for MobileCommunication (GSM) dan Code Division Multiple Access (CDMA) atau sarana komunikasi yang ada telah lumpuh. Automatic Packet Reporting System (APRS) merupakan aplikasi paket radio untuk pengiriman datayang cepat dan terpercaya dan merupakan protokolkomunikasi yang secara real-time diperuntukkan bagipertukaran atau penyampaian data dalam jumlah besar dalam jaringan secara multi-user. Banyak kemajuan di bidang komunikasi nirkabel dan embedded system yangtelah dibuat skema modulasi sistem yang lebih baik(Matondang \& Adityawarman, 2018).

Penelitian ini merujuk pada penelitian sebelumnya yakni Potensi Pemanfaatan Sistem APRS Untuk SaranaPenyebaran Informasi Kondisi Cuaca Antariksa (Dear, 2010), Sistem Stasiun Bumi PemancardanPenerima Data APRS Pada Satelit Lapan-A2 APRS Ground Station System On LAPAN-A2Satellite (Ardinal \& Harsono, 2018), Implementasi Automatic Packet Reporting System (APRS) Untuk Paket Data Pemantauan dan Pengukuran(Goeritno et al., n.d.), Implementation of APRS Network Using LoRa Modulation Based KISS TNC(Matondang \& Adityawarman, 2018) dan Comparasion Of Rainfall Analysis Of Jaxa Satellite Rainfall Data On Stations Data In Jambi (Susanti et al., 2020).

Perbedaan penelitian ini dengan penelitian sebelumnyaadalah menganalisis potensi pengguna sistem aprs berdasarkan jumlah dan pengukuran data oleh sistem APRS Internet System (APRS-IS) pada situs aprs.fi berdasarkan data samplingtitik koordinat yang diambil secara acak.Penelitian ini penting dilakukankarenadengan adanya paket data yang diambil dari sistem APRS Internet System (APRS-IS) pada situs aprs.fi diyakini mampu menyediakan data telemetri penyebarluasan informasi kondisi cuaca, pengukuran 


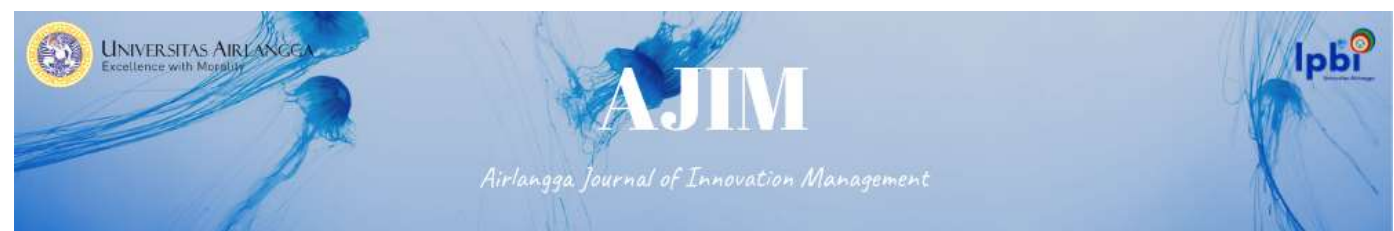

kelembaban udara serta tekanan arah mata angin secara real time berdasarkan kebutuhan sistem yang ada.

\section{KAJIAN PUSTAKA}

Automatic Packet Reporting System (APRS)pada awalnya digunakan untuk menentukan koordinat posisi saja atau dikenal dengan Automatic Positioning Reporting System. Sistem APRS adalah sistem yang dibangun untuk menampilkan data koordinat dan pertukaran grafik informasi antara partisipan dalam suatu kegiatan. APRS ini tidak hanya digunakan untuk tracking dan pemantauan data posisi, tetapi juga status, pesan, serta data telemetri tanpa menggunakan koneksi paket data. APRS terdiri dari jaringan wireless yang sangat besar, pemakainya saat ini hampir mencapai 40.000 di seluruh dunia. Jaringan ini bekerja dengan RELAYS setiap 20-30 panggilan "digipeaters" dengan serentak melalui IGates ke Internet(Ardinal \& Harsono, 2018).

Cara kerja Automatic PacketReporting System (APRS) yakni dengan memanfaatkan sensor-sensor yang terpasang, kinerja sensor yang dilakukan melalui proses perekaman pada stasiun penerimaan data APRS. Dalam hal ini, data yang dilaporkan oleh tiap posisi sesuai dengan titik koordinat yang ditentukan sebetulnya dapat dimanfaatkan untuk kepentingan banyak hal seperti prediksi cuaca, pengukuran kelembaban udara serta tekanan dan arah mata angin. Bahkan kinerja sensor-sensor dapat diamati pada stasiun pengiriman dan data hasil dari pengamatan tersebut dapat diterima pada stasiun penerimaan paket data secara real time(Goeritno et al., n.d.).

Konfigurasi sistem APRS pada stasiun tetap memerlukan perangkat keras berupa radio transceiver, personal komputer dan sebuah interface radio komputer. Sedangkan untuk stasiun yang bergerak, kebutuhan perangkat yang digunakan dapat dieliminasi apabila fungsi yang digunakan hanya bertujuan untuk memancarkan informasi saja.
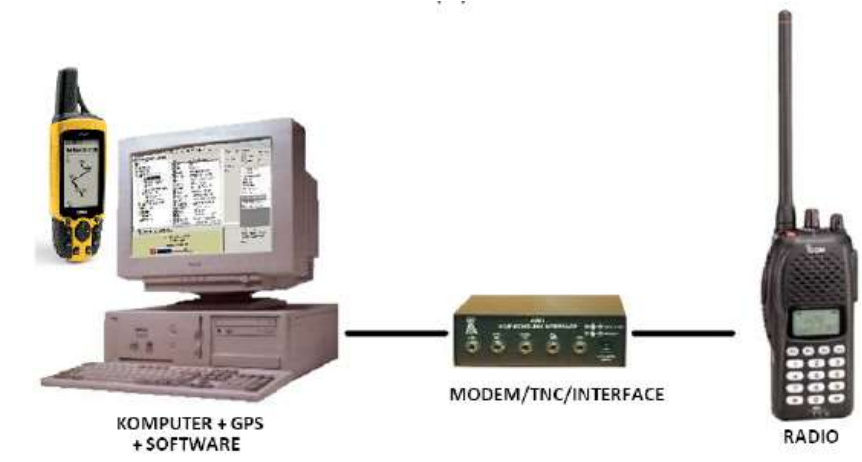

Gambar 1. APRS Monitoring

Sumber: Peneliti Bidang Ionosfer dan Telekomunikasi, LAPAN (Dear, 2010)

Sistem APRS yang hanya memancarkan informasi saja umumnya digunakan sebagai sinyal yang disiapkan agar dapat dilacak/diketahui lokasinya oleh penerima (APRS Tracker). 


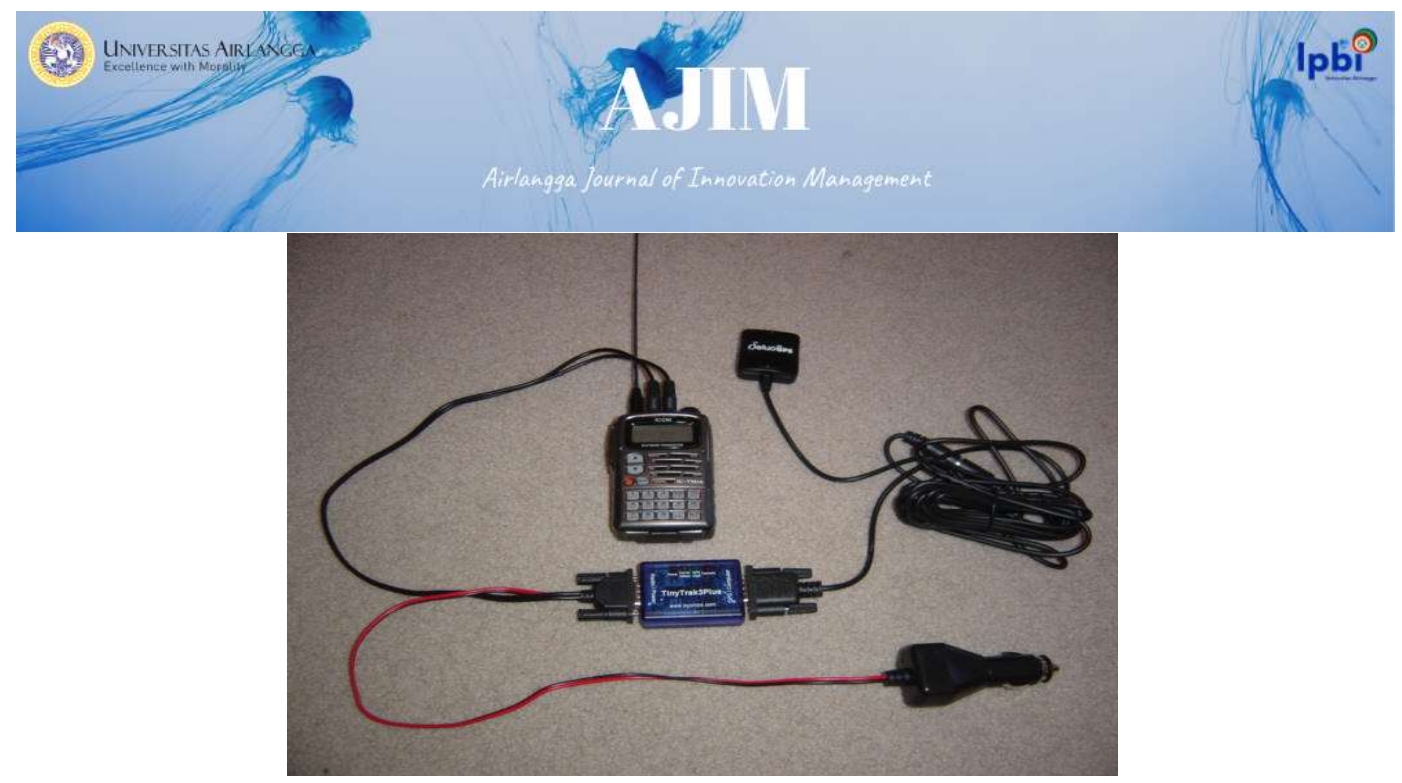

Gambar 2. APRS GPS TrackerSinyal Suar (Beacon) Sumber: Dokumen Pribadi, 2020

Penerapan sistem APRS pada sebuah stasiun radio dapat dilakukan secara sederhana dengan menggunakan perangkat yang murah dan mudah diperoleh.Frekuensi yang digunakan dalam sistem APRS terdapat pada beberapa pita frekuensi. Untuk pita frekuensi HF (High Frequency), frekuensi yang digunakan adalah frekuensi $10.151 \mathrm{MHz}$ LSB. Sedangkan untuk pita frekuensi VHF (Very High Fequency), frekuensi yang digunakan umumnya berada pada band 2-meteran yakni 144,390MHz(Dear, 2010). Di Indonesia, frekuensi $144,390 \mathrm{MHz}$ merupakan frekuensi yang dialokasikan untuk para amatir radio yang tergabung dalam organisasi Organisasi Radio Amatir Republik Indonesia (ORARI). Penggunaan pada frekuensi tersebut dapat juga diakses oleh setiap orang, namun hanya sebatas memonitor saja. Apabila ingin ikut aktif melakukan komunikasi menggunakan frekuensitersebut, maka operator tersebut harus tergabung dalam organisasi ORARI.

Tabel 1. Beberapa Alokasi Frekuensi Untuk Sistem APRS

\begin{tabular}{lll}
\hline Pita Frekuensi & Frekuensi & Keterangan \\
\hline HF & $10,14 \mathrm{MHz}$ & USB mode \\
VHF & $144,39 \mathrm{MHz}$ & USA, Indonesia \\
UHF & $439.100 \mathrm{MHz}$ & Melbourne \\
\hline
\end{tabular}

\section{Internet Of Things (IoT)}

\section{Sumber: Dear (2010)}

Internet of Things (IoT) adalah sebuah konsep/skenario suatu objek yang memiliki kemampuan untuk mentransfer data melalui jaringan tanpa memerlukan interaksi manusiake manusia atau manusia ke komputer. IoT telah berkembang dari konvergensi teknologi nirkabel,microelectromechanical systems (MEMS), dan Internet. Kata "A Things" pada Internet of Things dapat didefinisikan sebagaisubjek misalkan orang dengan monitor implant jantung, hewan peternakan dengan transponder biochip, sebuah mobil yang telah dilengkapi built-in sensor untuk memperingatkan pengemudi ketika tekanan ban rendah. Sejauh ini, IoT paling erat hubungannya dengan komunikasi machine-tomachine (M2M) di bidang manufaktur dan listrik, perminyakan, dan gas(Mudjanarko, Winardi, \& Limantara, 2017). Produk sistem dibangun dengan kemampuan komunikasi 


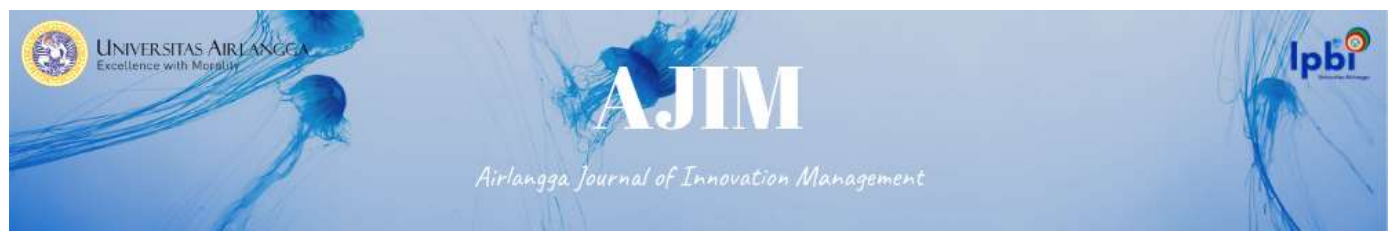

M2M yang sering disebut dengan sistem cerdas atau "smart", sepertismart label, smart meter, smart grid sensor.

Tabel 2. M2M Connections Berdasarkan Regional

\begin{tabular}{cccc}
\hline Region & $\begin{array}{c}\text { M2M \% Total } \\
\text { Connection (2013) }\end{array}$ & $\begin{array}{c}\text { M2M CAGR } \\
(2010-2013)\end{array}$ & $\begin{array}{c}\text { Connections } \\
\text { CAGR } \\
(2010-2013)\end{array}$ \\
\hline Africa & $1.0 \%$ & $41.3 \%$ & $15.0 \%$ \\
Asia & $2.1 \%$ & $55.0 \%$ & $10.4 \%$ \\
Europe & $5.1 \%$ & $28.6 \%$ & $2.4 \%$ \\
Latin America & $2.1 \%$ & $43.7 \%$ & $7.8 \%$ \\
Northern America & $9.3 \%$ & $22.5 \%$ & $\mathbf{3 . 6 \%}$ \\
Ocenia & $\mathbf{5 . 1 \%}$ & $\mathbf{2 5 . 8 \%}$ & $\mathbf{5 . 5 \%}$ \\
Global & $\mathbf{2 . 8 \%}$ & $\mathbf{3 7 . 6 \%}$ & $\mathbf{8 . 8 \%}$ \\
\hline
\end{tabular}

Sumber: (“Understanding the Internet of Things ( IoT )," 2014)

Cara kerja IoT dengan memanfaatkan suatu argumen pemograman(Shinde \& ware, 2018), tiap-tiap perintah argumen tersebut dapat menghasilkan suatu interaksi antar mesin yang telah terhubung secara otomatis tanpa campur tangan manusia dan tanpa terbatas jarak berapapun jauhnya(Lestari, 2018). Jadi, internet menjadi penghubung antara kedua interaksi kedua mesin tersebut. Manusia dalam IoT hanyalah menjadi pengatur dan pengawas dari mesin-mesin yang bekerja secara langsung tersebut. Adapun unsur-unsur pembentukan IoT yang mendasar adalah Kecerdasan Buatan (Artificial Intelligence/AI), Konektivitas, Sensor, Keterlibatan Aktif (Active Engagement) dan Perangkat Berukuran Kecil(Arduino Board).

\section{METODE}

Metodologi yang dilakukan dalam penelitian ini adalah menganalisis potensi pengguna sistem APRS berdasarkan jumlah dan karakteristik pengguna sistem tersebut dengan melakukan observasi dan pengukuran keakuratan data pada sistem APRS Internet System (APRS-IS) dan situs aprs.fi. Dengan diketahuinya jumlah dan beberapa karakter pengguna yang teramati, maka dapat diketahui besarnya potensi penerapan sistem APRS sebagai salah satu infrastruktur penyebaran informasi kondisi cuaca antariksa. Stasiun APRS yang digunakan untuk pengamatan merupakan stasiun APRS yang berlokasi di Ciputat, West Java, Indonesia berlokasi koordinat $6^{\circ} 15.23^{\prime} \mathrm{S} 106^{\circ} 45.30^{\prime} \mathrm{E}$, callsign YE0EEE-3 dengan frekuensi kerja 144,390MHz, Pamulang, West Java, Indonesialokasi koordinat $6^{\circ} 20.26^{\prime} \mathrm{S} 106^{\circ} 43.38^{\prime} \mathrm{E}$, callsign YD0SPU-13 dengan frekuensi kerja $144,390 \mathrm{MHz}$ dan bandara udara internasioal soekarno hatta lokasi koordinat $6^{\circ} 07.00^{\prime} \mathrm{S}$ $106^{\circ} 39.00^{\prime} \mathrm{E}$ dengan weather station's callsign WIII frekuensi kerja $144,390 \mathrm{MHz}$. Pengamatan dilakukan selama 24 jam antara tanggal 01-02-2020 06:06:00 wib - 12-022020 pukul 18:22:00 wib. 

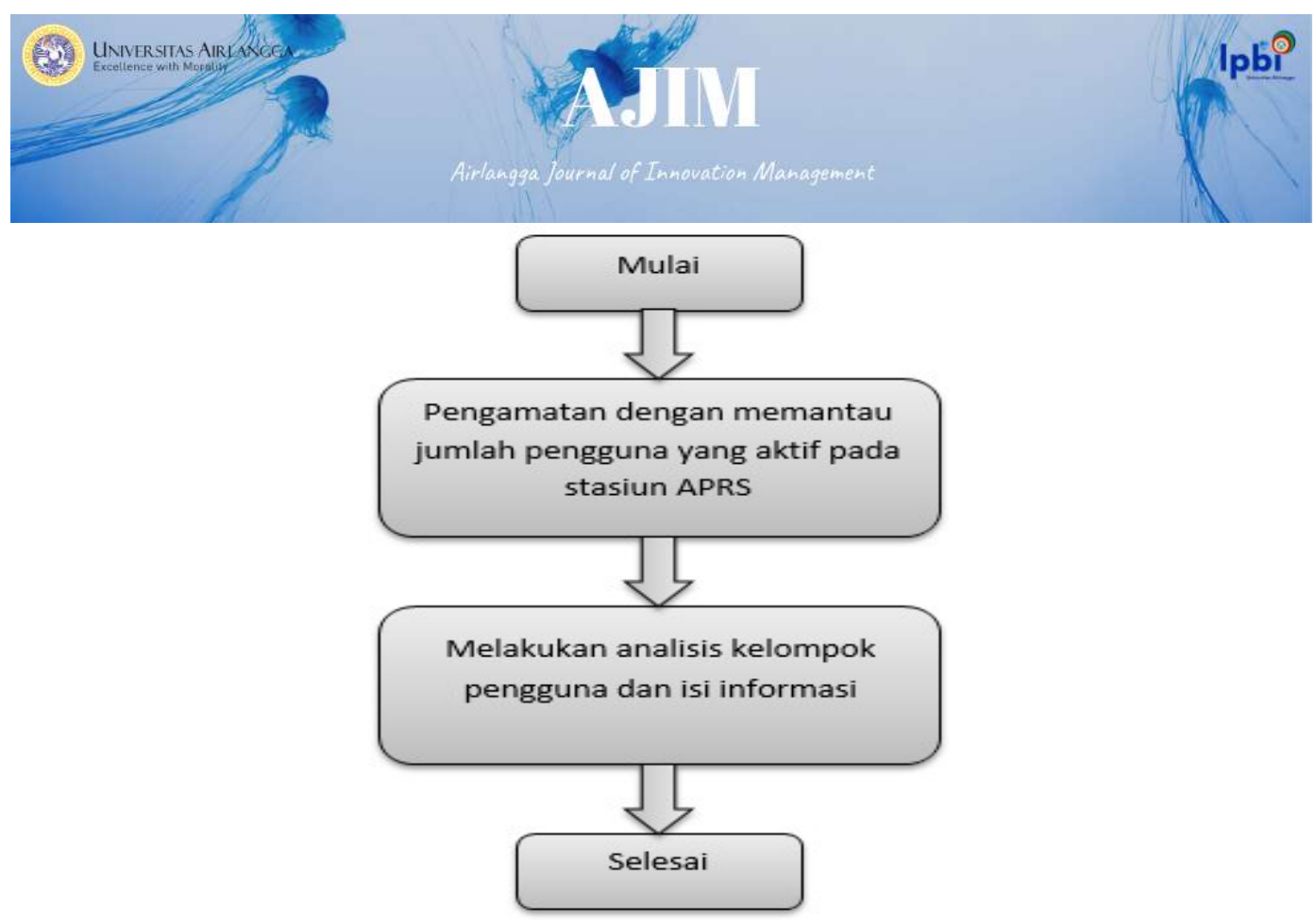

Gambar 3. Langkah-langkah Penelitian

Tabel 3. Perangkat Stasiun APRS di Ciputat, West Java, Indonesia $6^{\circ} 15.23$ ' S $106^{\circ} 45.30^{\prime}$ E, Pamulang, West Java, Indonesia $6^{\circ} 20.26^{\prime}$ S $106^{\circ} 43.38^{\prime}$ E, dan bandara udara internasioal soekarno hatta $6^{\circ} 07.00^{\prime} \mathrm{S} 106^{\circ} 39.00^{\prime} \mathrm{E}$.

\section{$\begin{array}{lll}\text { Perangkat } & \text { Frekuensi } & \text { Callsign }\end{array}$}

Linux Raspberry Pi, Argent Data Systems: OpenTracker (tracker),Roger Barker, G4IDE: UI-View32 (software,

Windows), Kenneth W. Finnegan, W6KWF: Aprx (software, Linux/Unix), Kenneth W. Finnegan, W6KWF: Aprx (software,

Linux/Unix), Argent Data Systems: OpenTracker (tracker), Kenneth W. Finnegan, W6KWF: Aprx (software, Linux/Unix), Kenwood: TH-D7 (ht), Argent Data Systems: OpenTracker (tracker)

APRS/CWOP Program via TCPIP*,qAC,T2GYOR,AB0WV:

PinPoint, Open Source: APRSdroid (app, Android)

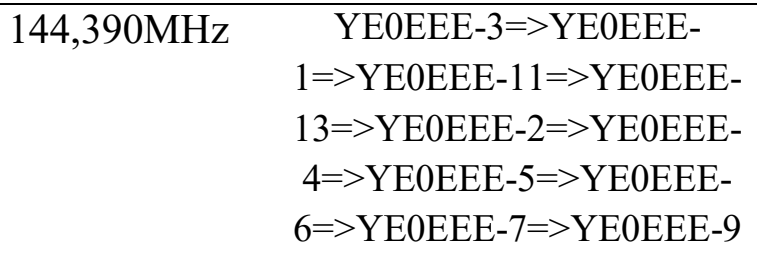

$144,390 \mathrm{MHz}$

YD0SPU-

$13=>$ YD0SPU $=>$ YD0SPU -5

APRS/CWOP Program via TCP/IP, qAS,KK5WM-2

\section{HASIL DAN PEMBAHASAN}

Berdasarkan pengamatan secara realtimeyangdilakukan selama 24 jam antara tanggal 03-02-2020 pukul 18:45:44 WIB - 05-02-2020 pukul 18:45:44 WIB pada sistem 


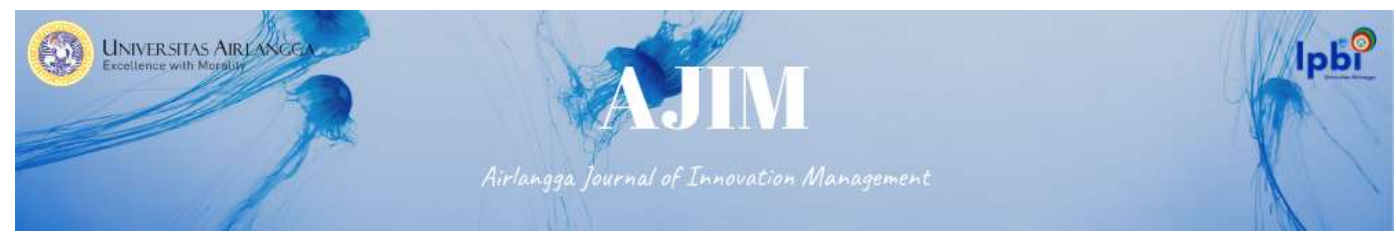

APRS Internet System (APRS-IS) dan situs aprs.fibahwa terdapat beberapa informasi yang didapatkan baik dari jumlah pengguna yang memancarkan sinyal suar (Beacon)APRS GPS Trackerdan penggunaAPRS Monitoring. Terdapat beberapa stasiun terpantaupada peta jabodetabek indonesia yang memiliki beragam callsignberbeda-beda serta beberapa simbol yang unik.

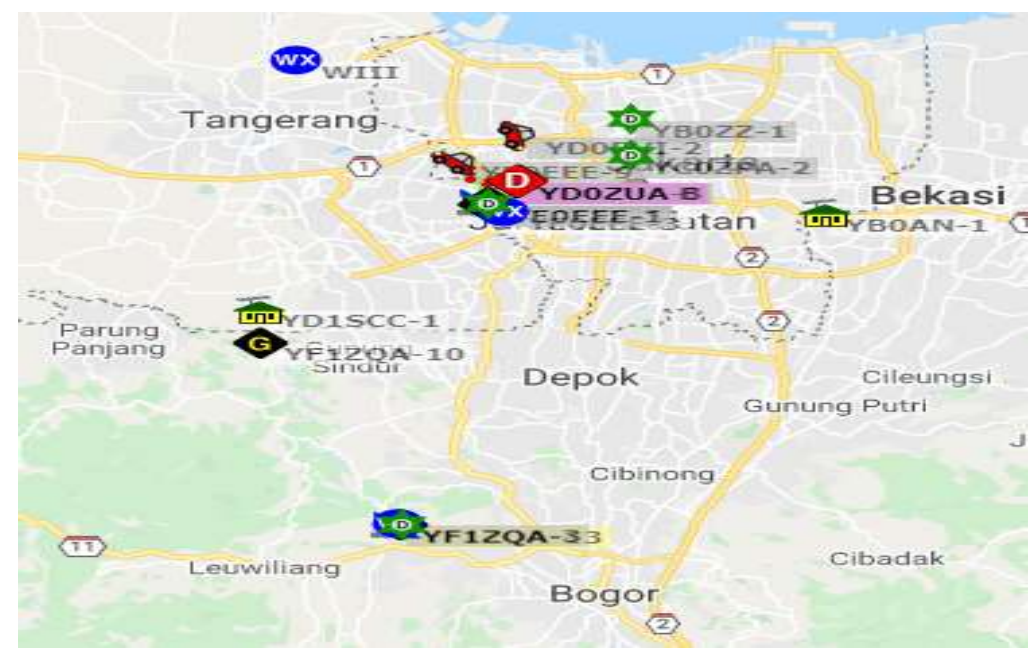

Gambar 4.Aneka Simbol Stasiun APRS yang Terpantau di Jabodetabek Pada Saat Pengamatan pada Sistem APRS-IS

Sumber: data diproses penulis

Terdapat beberapa informasi yang didapatkan diantaranya titik koordinat lokasi, Last WX report yang dikirimkan secara real time mulai tanggal 01/02/2020 sampai pada tanggal 12/02/2020 pukul 18:22:04 WIB.

Tabel 4. Hasil Pemantauan Kondisi Cuaca Stasiun Ciputat, West Java, Indonesia $6^{\circ} 15.23$ ' S 106 ${ }^{\circ} 45.30^{\prime}$ 'Ecallsign YEOEEE-3

\begin{tabular}{ll} 
Comment: & leCumulusFOs \\
Location: & $6^{\circ} 15.23^{\prime} \mathrm{S} 106^{\circ} 45.30^{\prime} \mathrm{E}-$ locator OI33JR09OB \\
& $6.8 \mathrm{~km}$ East bearing $105^{\circ}$ from Ciputat, West Java, Indonesia \\
& $10.1 \mathrm{~km}$ North bearing $11^{\circ}$ from Pamulang, West Java, Indonesia \\
& $10.9 \mathrm{~km}$ Southwest bearing $246^{\circ}$ from Jakarta, Jakarta Raya, Indonesia \\
& $119.6 \mathrm{~km}$ Northwest bearing $307^{\circ}$ from Bandung, West Java, Indonesia \\
\hline
\end{tabular}

Last position:2020-02-12 18:22:04 WIB (57s ago)

2020-02-12 18:22:04 WIB local time at Ciputat, Indonesia

Last WX report: 2020-02-12 18:14:03 WIB (1h15m ago)

2020-02-12 18:14:03 WIB local time at Ciputat, Indonesia

Temperature: $30.0^{\circ} \mathrm{C}$

Dew point: $22.4^{\circ} \mathrm{C}$

Humidity: $64 \%$

Pressure: $1011.5 \mathrm{mbar}$

Wind: East $83^{\circ} 0.9 \mathrm{~m} / \mathrm{s}$ (Gusts $2.2 \mathrm{~m} / \mathrm{s}$ )

Rain:0.0 mm during last 1 hour, $0.0 \mathrm{~mm}$ during last 24 hours, $0.0 \mathrm{~mm}$ since midnight

Luminosity: $1129 \mathrm{~W} / \mathrm{m}^{2}$

Sumber: Hasil Pengamatan Penulis

107|Airlangga Journal of Innovation Management, Vol.1 (1) June 2020 


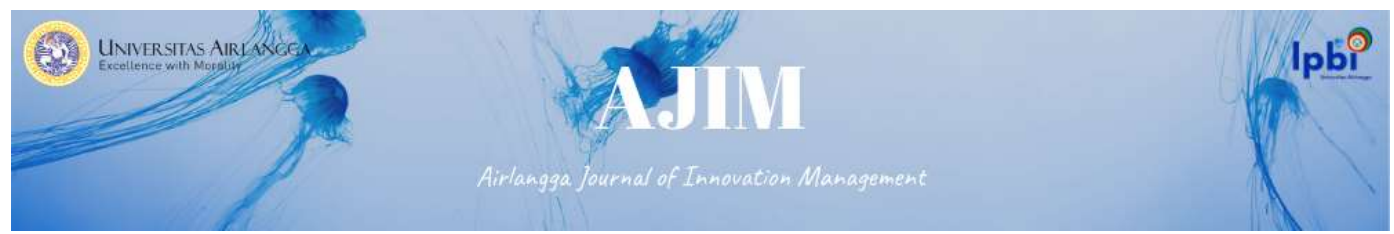

Tabel 5.Hasil Pemantauan Kondisi Cuaca StasiunPamulang, West Java, Indonesia6 ${ }^{\circ} 20.26$ ' S $106^{\circ} 43.38$ ' ECallsign YD0SPU-13

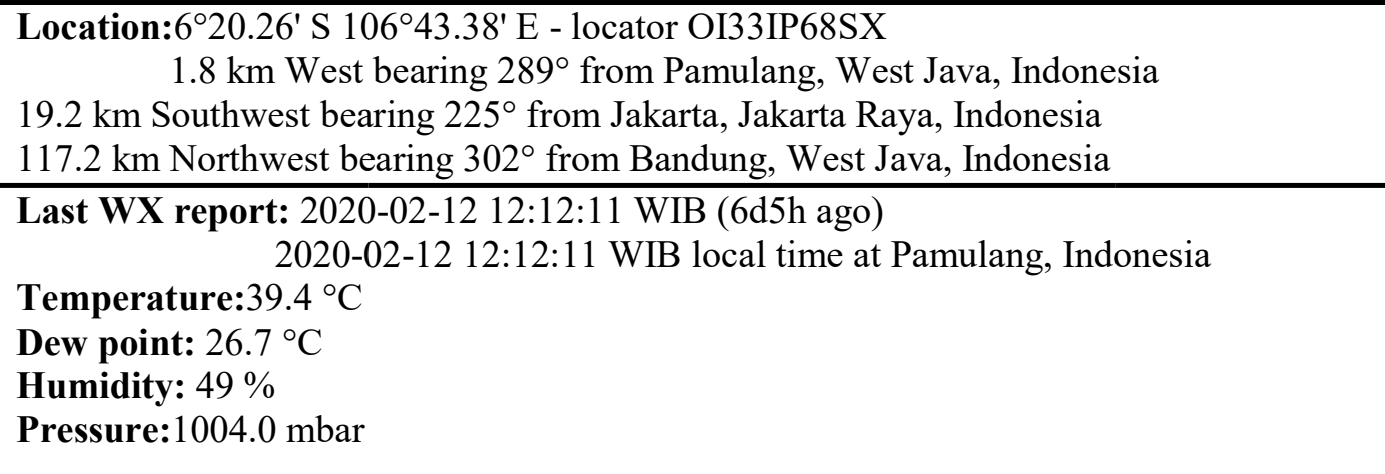

Sumber: Hasil pengamatan penulis

Tabel 6.Hasil Pemantauan Kondisi Cuaca StasiunBandara Udara Internasioal Soekarno Hatta $6^{\circ} 07.00^{\prime}$ S $106^{\circ} 39.00^{\prime}$ E Callsign WIII

Comment: Indonesia_Jakarta/Soekarno-Hatta

Location: $\quad 6^{\circ} 07.00^{\prime} \mathrm{S} 106^{\circ} 39.00^{\prime} \mathrm{E}$ - locator OI33HV81AX

$2.4 \mathrm{~km}$ Southeast bearing $146^{\circ}$ from Teluknaga, West Java, Indonesia

$7.2 \mathrm{~km}$ North bearing $18^{\circ}$ from Tangerang, West Java, Indonesia

$24.1 \mathrm{~km}$ Northwest bearing $297^{\circ}$ from Jakarta, Jakarta Raya, Indonesia

$138.2 \mathrm{~km}$ Northwest bearing $309^{\circ}$ from Bandung, West Java, Indonesia

Last WX report:2020-02-18 19:13:14 WIB (28m ago)

2020-02-18 19:13:14 WIB local time at Teluknaga, Indonesia

Temperature: $27.8^{\circ} \mathrm{C}$

Dew point: $23.6^{\circ} \mathrm{C}$

Humidity: $78 \%$

Pressure: $1010.0 \mathrm{mbar}$

Wind:West $290^{\circ} 1.3 \mathrm{~m} / \mathrm{s}$

Sumber: Hasil Pengamatan Penulis

Dari hasil pengamatan temperatur mengalami kenaikan pada tanggal 1 februari 2020 yang semula $25.6{ }^{\circ} \mathrm{C}$ menjadi $30.0^{\circ} \mathrm{C}$ sampai tanggal $12 / 02 / 2020$ pukul 18:22:04 WIB, Dew Point (titik embun udara) mengalami penurunan yang tidak signifikan pada tanggal 1 februari 2020 yang semula $26.3^{\circ} \mathrm{C}$ menjadi $22.4^{\circ} \mathrm{C}$ sampai tanggal $12 / 02 / 2020$ pukul 18:22:04 WIB. Dew Point $-20^{\circ} \mathrm{C}$ artinya udara hanya akan mengembun menjadi air ketika suhu turun menjadi $-20^{\circ} \mathrm{C}$. Titik-titik air tidak akan timbul jika suhunya masih di atas $-20^{\circ} \mathrm{C}$. Seperti suhu di Indonesia umumnya yang +20 -an ${ }^{\circ} \mathrm{C}$ maka udara dengan dew-point $-20{ }^{\circ} \mathrm{C}$ tidak akan pernah mengembun menjadi air. Dapat disimpulkan berdasarkan Psychrometric Chart bahwa kondisi masih dalam kategori normal. 


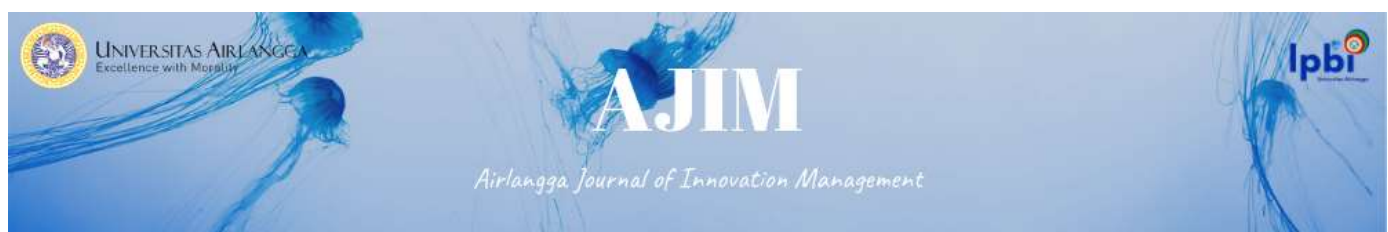

YEOEEE-3 Temperature 2020-02-01 13:00:00 -> 2020-02-12 20:00:00 WIB ${ }^{\circ} \mathrm{C}$

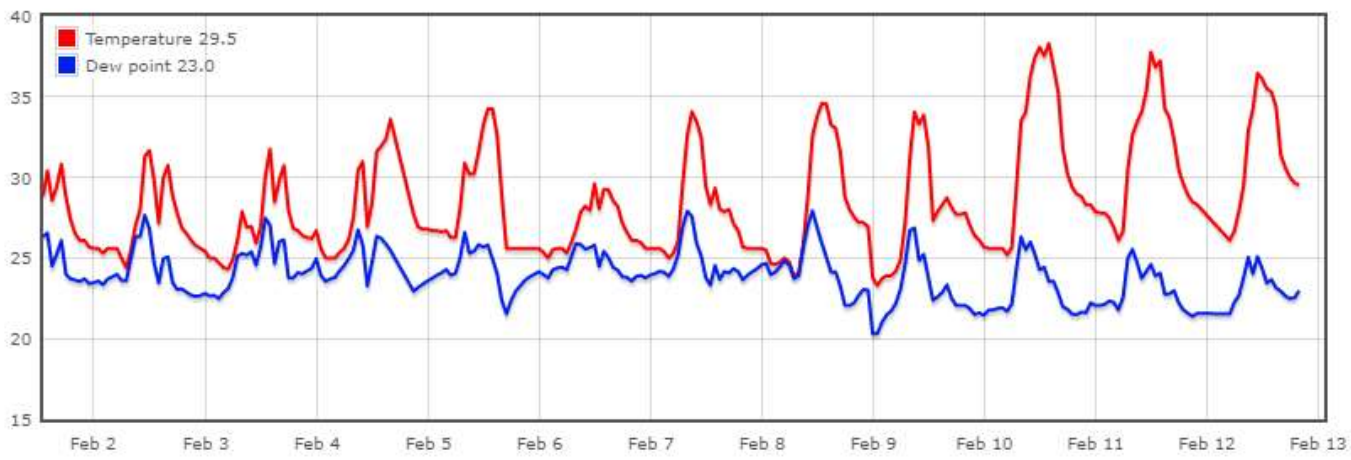

Gambar 5. Pemantauan Kondisi Temperature dan Dew PointcallsignYE0EEE-3 Sumber: Hasil Pengamatan Penulis

YD0SPU-13 Temperature 2020-02-01 13:00:00 -> 2020-02-12 12:00:00 WIB ${ }^{\circ} \mathrm{C}$

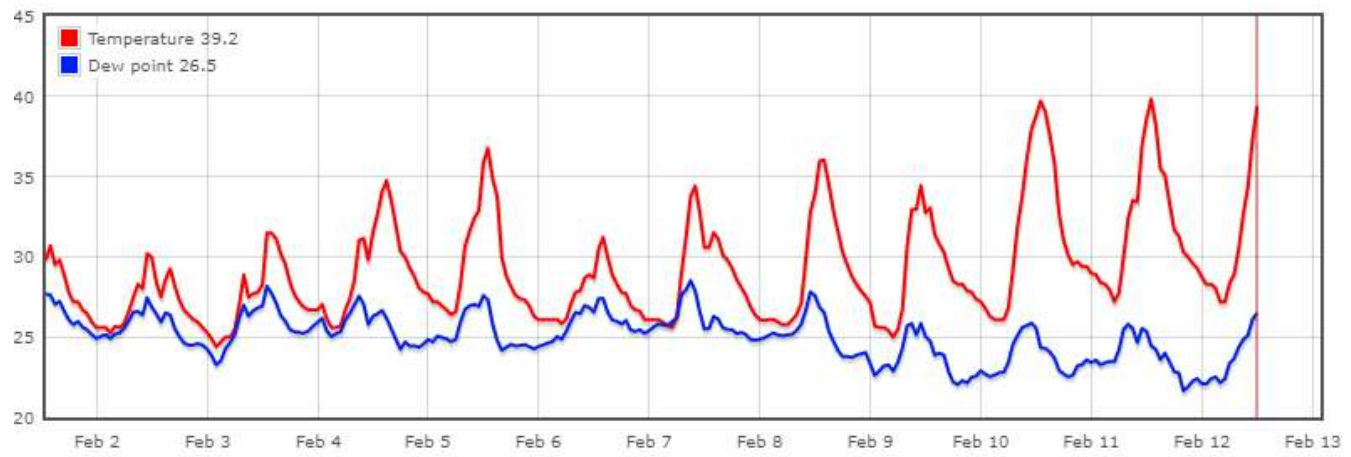

Gambar 6. Pemantauan Kondisi Temperature dan Dew PointcallsignYD0SPU-13 Sumber: Hasil Pengamatan Penulis

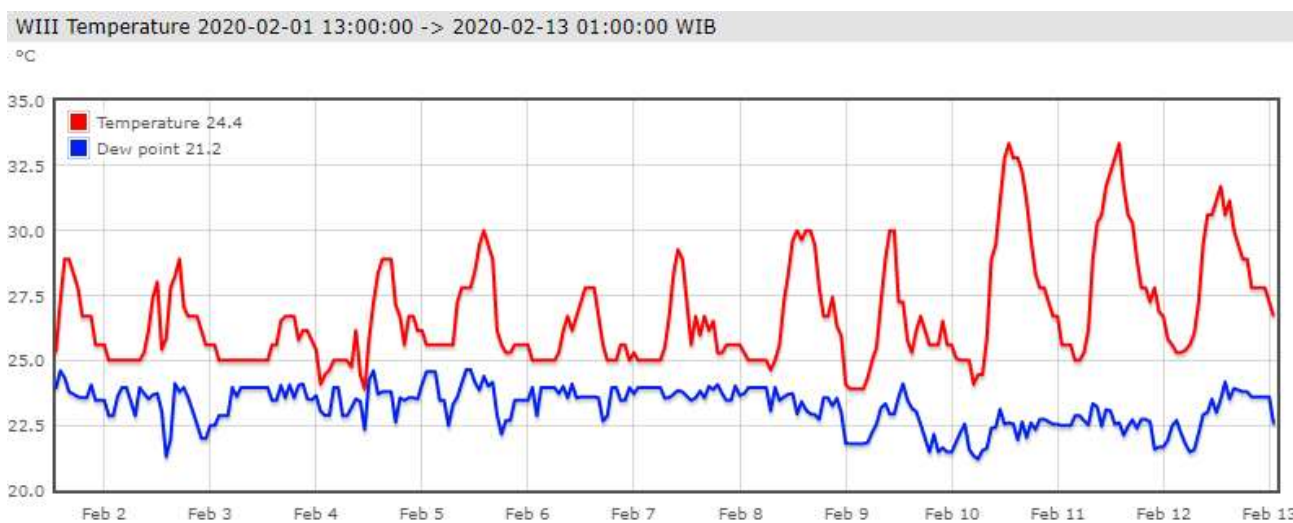

Gambar 7. Pemantauan Kondisi Temperature dan Dew PointcallsignWIII Sumber: Hasil Pengamatan Penulis 


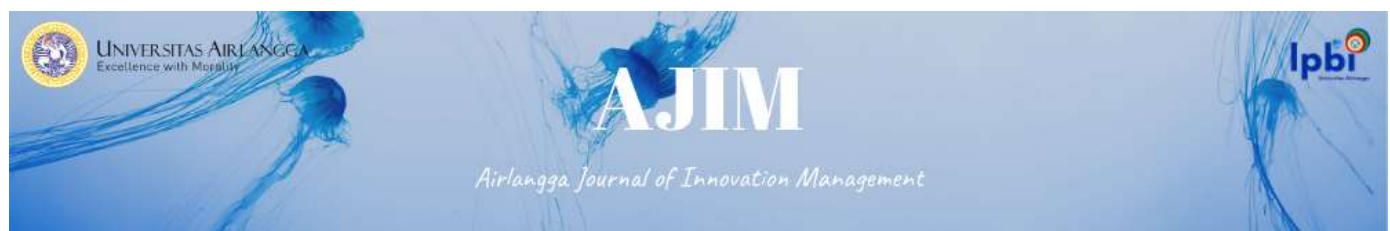

Berdasarkan pengamatan pada callsign YE0EEE-3 bahwa Humidity (kelembapan udara) sebanyak 64\%, menandakan bahwa kelembapan udara pada titik sedang, kelembapan relatif udara normal diiklim tropis pada suhu sekitar $28^{\circ} \mathrm{C}$ adalah sekitar $84 \%$. Kelembapan udara relatif $95 \%$ artinya udara mendekati jenuh kandungan airnya. Kelembaban relative $100 \%$ artinya udara sudah jenuh dan mengembun menjadi air (saturasi). Ketika kelembaban relative $100 \%$ maka dew point temperature akan sama dengan dry-bulb temperature.

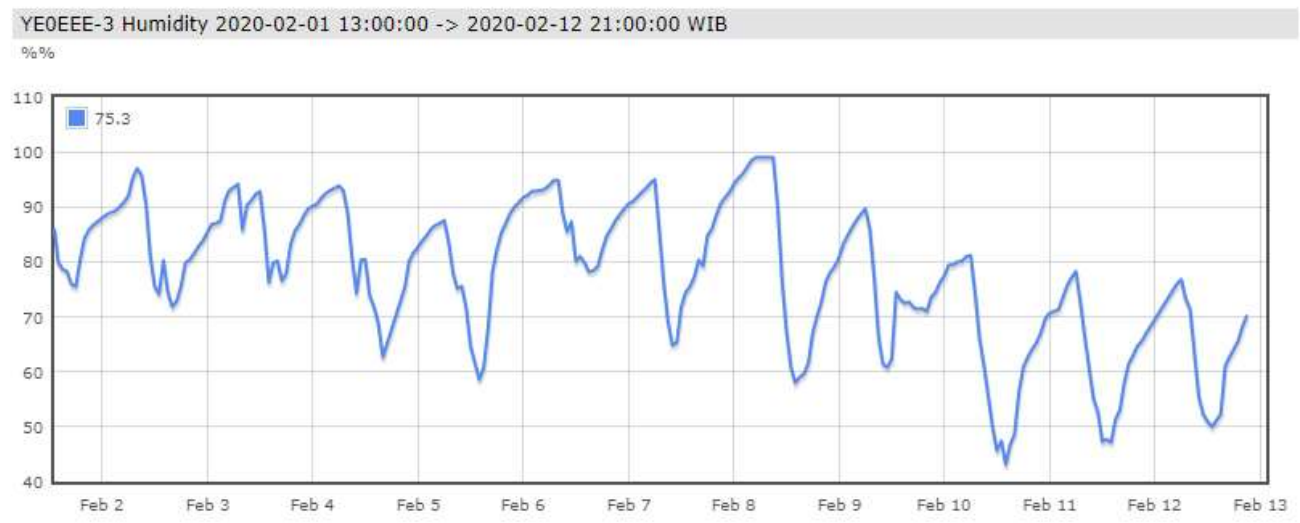

Gambar 8. Informasi Hasil Pemantauan Kondisi HumiditycallsignYE0EEE-3 Sumber: Hasil Pengamatan Penulis

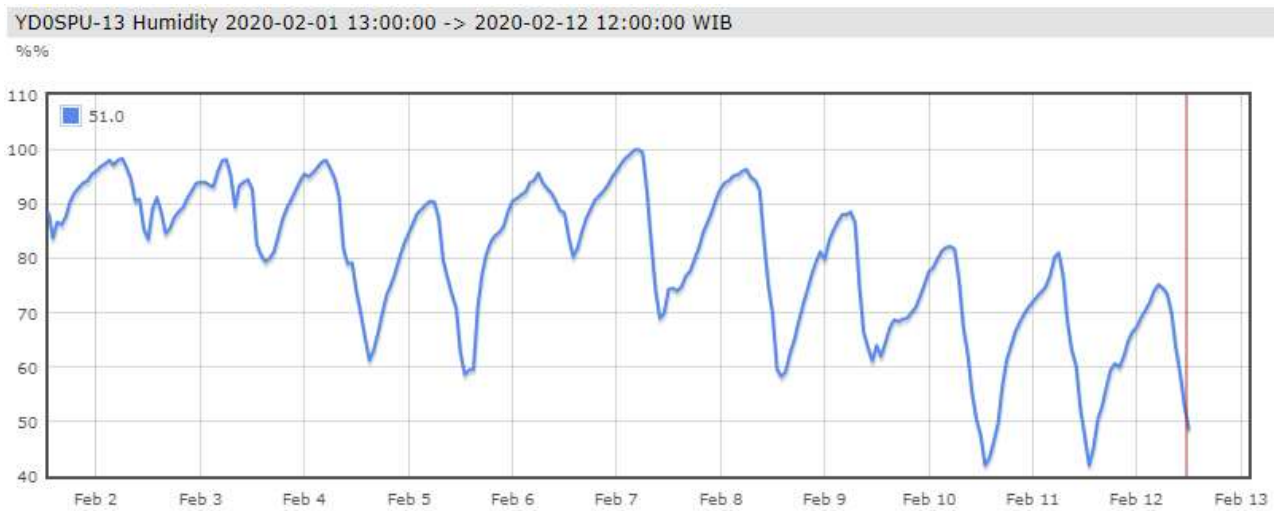

Gambar 9. Informasi Hasil Pemantauan Kondisi HumiditycallsignYD0SPU-13

Sumber: Hasil Pengamatan Penulis 


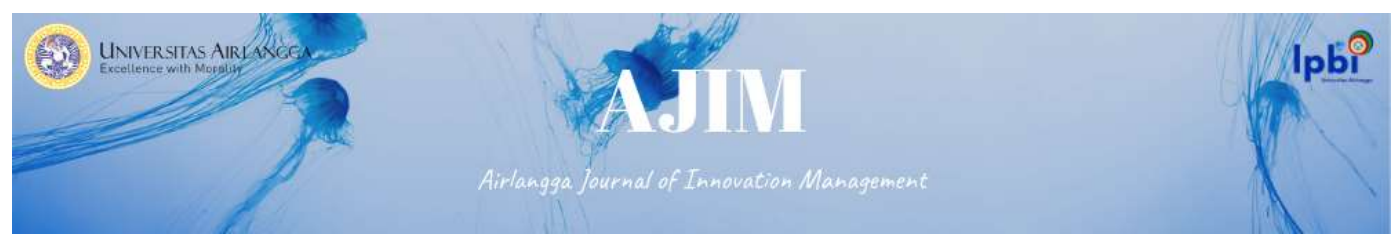

WIII Humidity 2020-02-01 13:00:00 -> 2020-02-13 01:00:00 WIB

$\% \%$

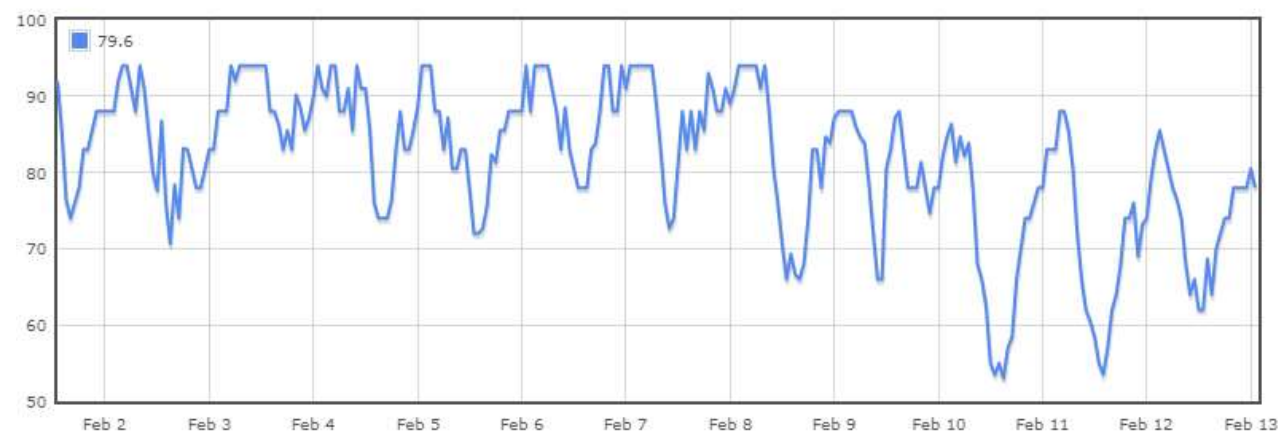

Gambar 10. Informasi Hasil Pemantauan Kondisi HumiditycallsignWIII

Sumber: Hasil Pengamatan Penulis

Berdasarkan pengamatan pada callsign YE0EEE-3 bahwa Pressure (Tekanan angin) sebesar $1011.5 \mathrm{mbar}$ (millibar) setara dengan $1.0115 \mathrm{bar}$.

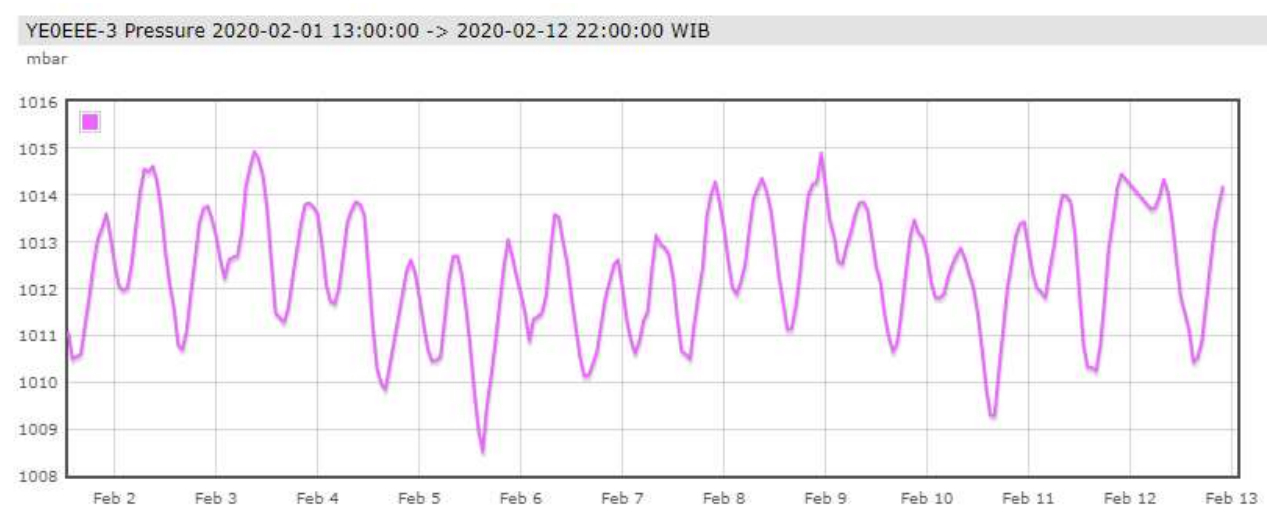

Gambar 11. Informasi Hasil Pemantauan Kondisi Pressure callsign YE0EEE-3

Sumber: Hasil Pengamatan Penulis

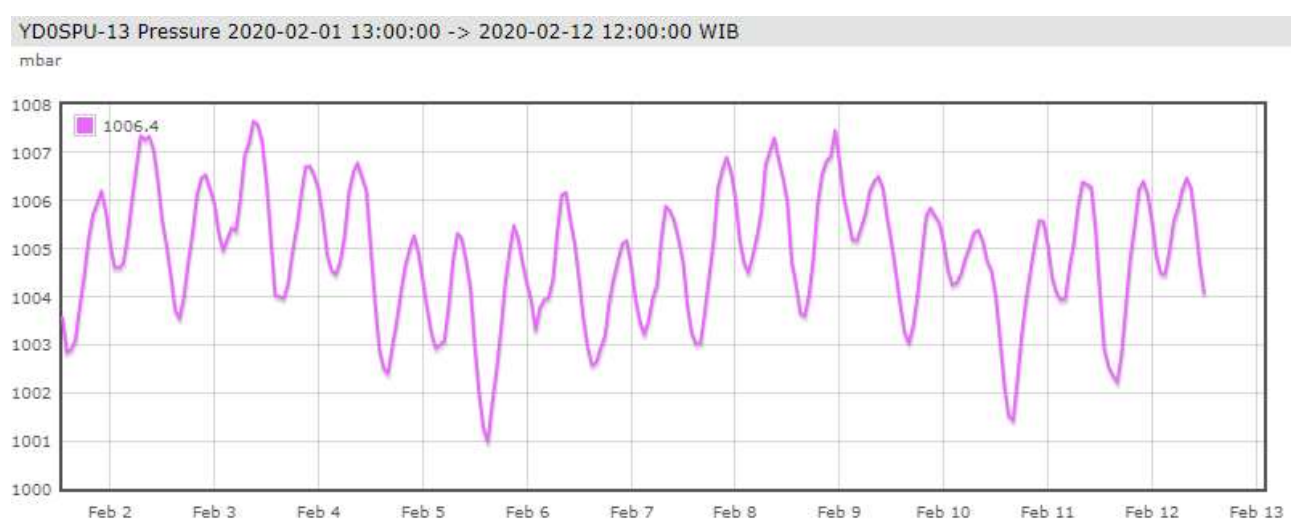

Gambar 12. Informasi Hasil Pemantauan Kondisi Pressure callsignYD0SPU-13 Sumber: Hasil Pengamatan Penulis 


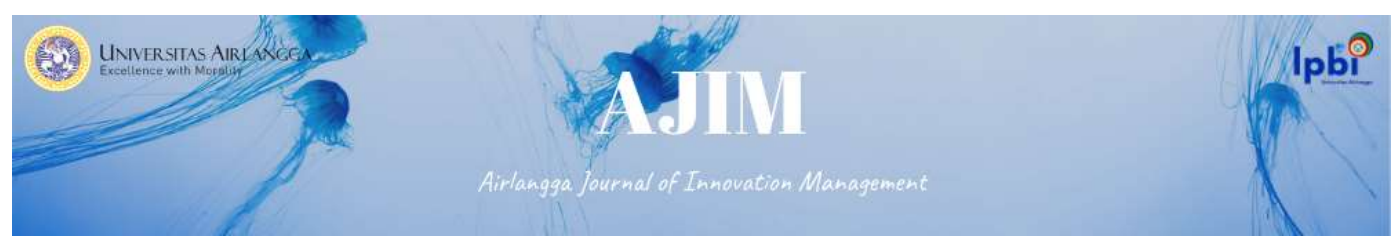

WIII Pressure 2020-02-01 13:00:00 -> 2020-02-13 01:00:00 WIB

mbar

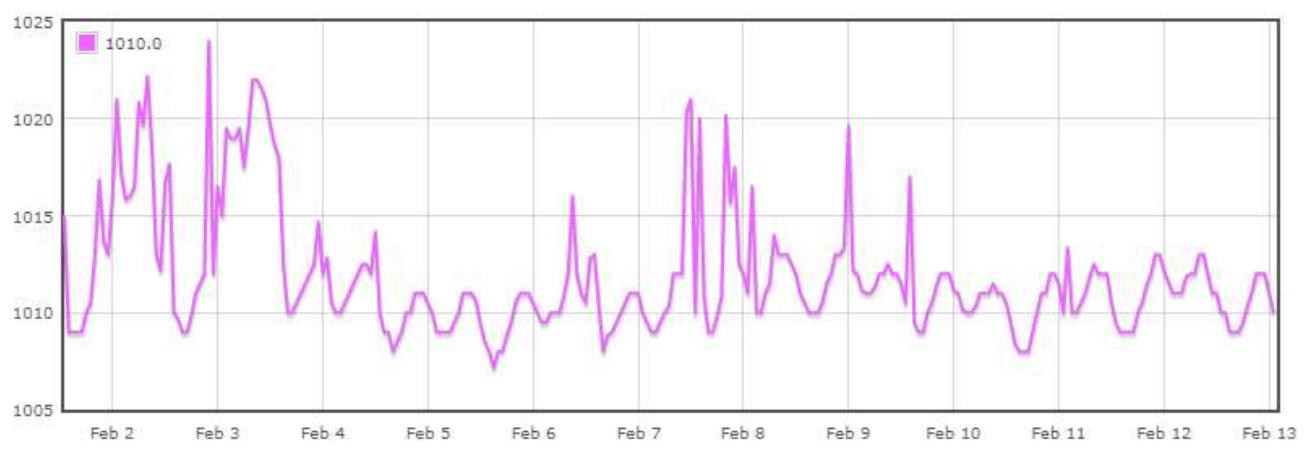

Gambar 13. Informasi Hasil Pemantauan Kondisi Pressure callsignWIII

Sumber: Hasil Pengamatan Penulis

Berdasarkan pengamatan pada callsign YE0EEE-3 bahwaWind (Angin) ke arah $\operatorname{East}$ (Timur) $83^{\circ} 0.9 \mathrm{~m} / \mathrm{s}$ dengan (Gusts $2.2 \mathrm{~m} / \mathrm{s}$ ). Gusts merupakan kecepatan angin maksimum dengan satuan milisecond.

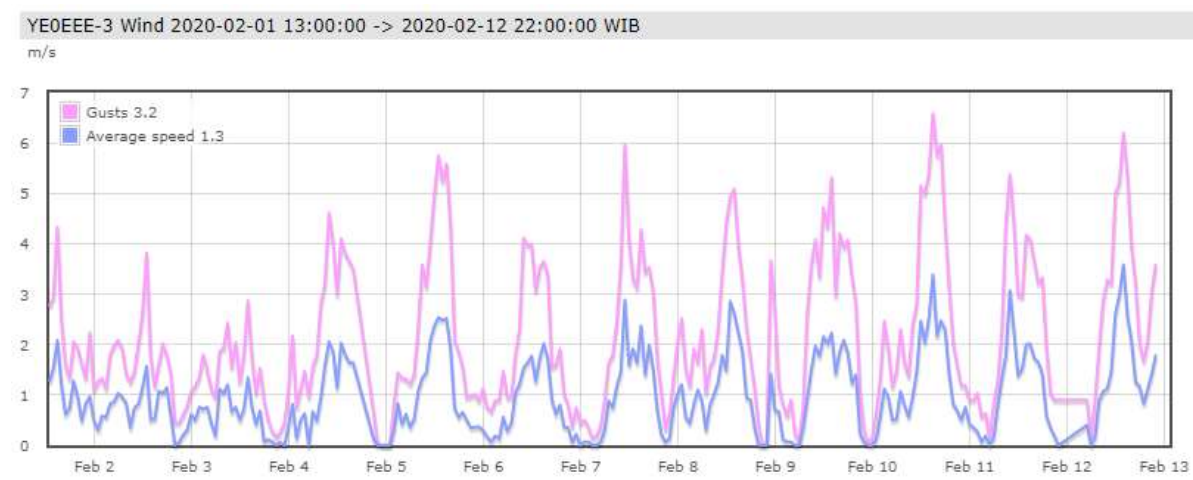

Gambar 14. Informasi Hasil Pemantauan Kondisi Wind callsignYE0EEE-3

Sumber: Hasil Pengamatan Penulis

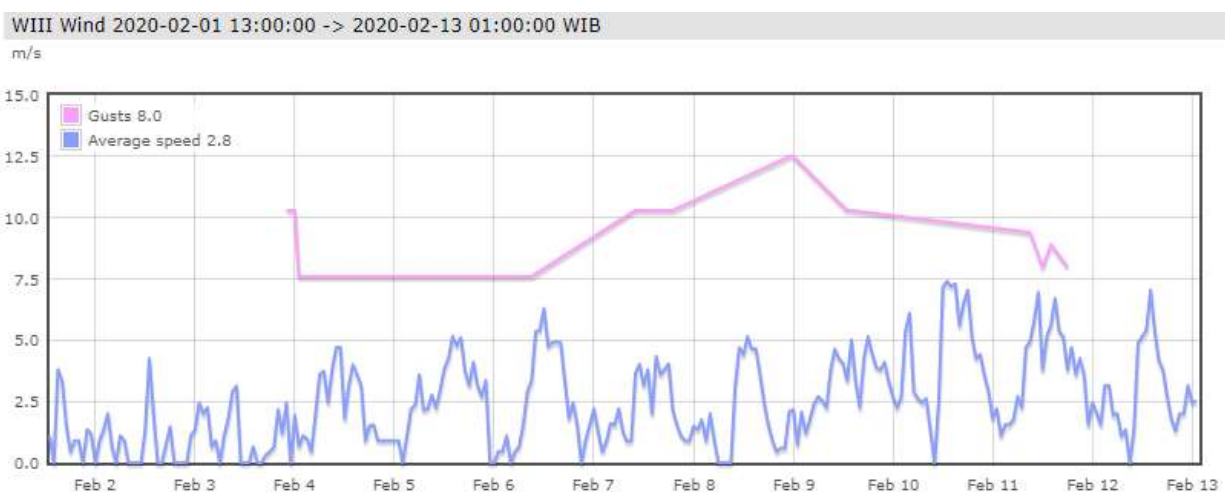

Gambar 15. Informasi Hasil Pemantauan Kondisi Wind callsignWIII Sumber: Hasil Pengamatan Penulis 


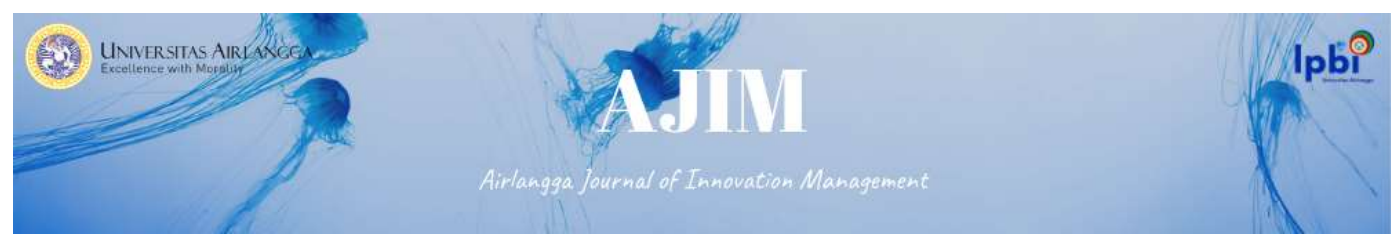

\section{KESIMPULAN}

Berdasarkan hasil penelitian dapat disimpulkan bahwa penggunaan teknologi IoT pada Automatic PacketReporting System (APRS)sebagai pengamatan cuaca, pengukuran kelembaban udara, tekanan arah mata angin dapat menjadi solusi saat ini. Pengetahuan tentang pemantauan cuaca menjadi faktor penting untuk berbagai keperluan menganalisis fenomena alam yang terjadijuga dapat disertakan jenis-jenis peringatan lainnya yang berkaitan dengan cuaca. Berdasarkan call sign yang tercatat, tingkat kemahiran operator radio didominasi oleh tingkat Pembina (YB) sebanyak 3 buah stasiun yaitu callsignYE0EEE-3, YD0SPU-13 dan WIII. Dengan tingkat kemahiran yang mencapai tingkat Pembina, maka hal ini dapat dijadikan pertimbangan bahwa operator tersebut menggunakan komunikasi radio pada pita HF. Selain diketahuinya tingkatan pengguna, informasi yang telah disajikan pada sistem APRS juga mencakup informasi kondisi alam seperti gempa bumi, curah hujan, tekanan angin dan suhu lingkungan di sekitar stasiun pemberi informasi. Kedua hal inilah yang dapat dinyatakan sebagai potensi pemanfaatan sistem APRS untuk informasi kondisi cuaca antariksa.

Saran untuk penelitian selanjutnya agar penggunaan teknologi IoT pada Automatic PacketReporting System (APRS)dapat didominasi dengan pengguna komunikasi radio pada pita HF yang dapat menyajikan informasi pada tiap titik koordinat khususnya pada area rawan bencana agar memudahkan prediksi kondisi cuaca dan alam khususnya di sekitar stasiun.

\section{DAFTAR PUSTAKA}

Ardinal, R., \& Harsono, S. D. (2018). Sistem Stasiun Bumi Pemancar Dan Penerima Data Aprs Pada Satelit Lapan-A2 Aprs Ground Station System On Lapan-A2 Satellite, $11-16$.

Bello, A. G., \& Torres, D. A. A. (2007). Design and construction of an agrometeorological monitoring system using APRS. Revista Colombiana de Tecnologias de Avanzada, 1(9), 127-132.

Bruninga, B. A General Overview of the APRS System-TCARC, Updated Jan 2006.

Chaiyasoonthorn, S., Hongyim, N., \& Mitatha, S. (2015, October). Building Automatic Packet Report System to report position and radiation data for autonomous robot in the disaster area. In 2015 15th International Conference on Control, Automation and Systems (ICCAS) (pp. 85-88). IEEE.

Dear, V. (2010). Potensi pemanfaatan sistem aprs untuk sarana penyebaran informasi kondisi cuaca antariksa, 11(3), 72-79.

Dunville, C. (2000). APRS- an introduction. Radio Communication, 76(12), 18-20.

Filjar, R., \& Desic, S. (2004, June). Architecture of the automatic position reporting system (APRS). In Proceedings. Elmar-2004. 46th International Symposium on Electronics in Marine (pp. 331-335). IEEE.

Gao, S., Ma, X., Zhu, J., \& Ma, J. (2017). APRS: a privacy-preserving location-aware recommender system based on differentially private histogram. Science China Information Sciences, 60(11), 119103.

Goeritno, A., Yatim, R., Penelitian, L., Elektro, J. T., Teknik, F., Ibn, U., \& Bogor, K. (n.d.). System ( APRS ) Untuk Paket Data Pemantauan, 27-34.

Lestari, N. S. (2018). Implementasi dan Optimalisasi Cloud Computing dalam Internet of Thinks (IoT). Jurnal Online Sekolah Tinggi Teknologi Mandala, 13(2), 100-107. 


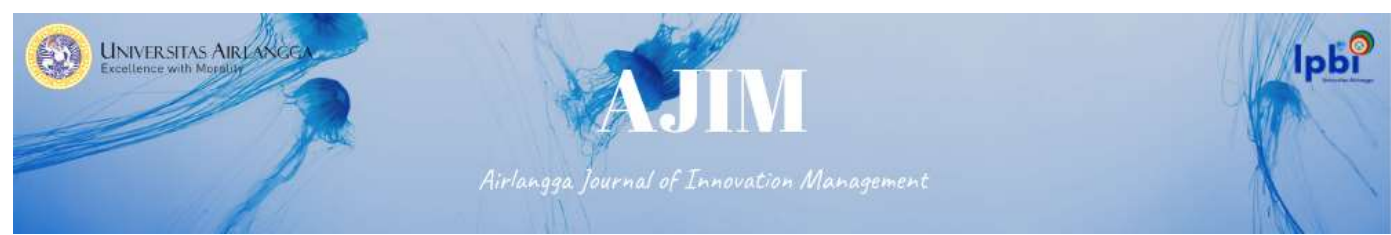

Lung, C., Oniga, S., Buchman, A., \& Tisan, A. (2013). Wireless data acquisition system for IoT applications. Carpathian Journal of Electronic and Computer Engineering, 6(1), 64.

Matondang, J., \& Adityawarman, Y. (2018). Implementation of APRS Network Using LoRa Modulation Based KISS TNC. 2018 International Conference on Radar, Antenna, Microwave, Electronics, and Telecommunications (ICRAMET), 37-40.

Mudjanarko, S. W., Winardi, S., \& Limantara, A. D. (2017). Pemanfaatan internet of things (iot) sebagai solusi manejemen transportasi kendaraan sepeda motor. Prosiding Seminar Nasional Aplikasi Teknologi Prasarana Wilayah X (ATPW), (August). https://doi.org/10.17605/OSF.IO/6UE4B.

Patmasari, R., Wijayanto, I., Deanto, R. S., Gautama, Y. P., \& Vidyaningtyas, H. (2018). Design and realization of automatic packet reporting system (APRS) for sending telemetry data in Nano satellite communication system. Journal of Measurements, Electronics, Communications, and Systems, 4(1), 1-7.

Prodoningrum, R. T., Wijanto, H., \& Prasetyo, A. D. (2015, August). Antenna deployment for Automatic Packet Reporting System of nanosatellite using Global Positioning System as a height sensor. In 2015 International Conference on Quality in Research (QiR) (pp. 8-11). IEEE.

Shinde, S. M., \& ware, J. D. N. (2018). IOT (Internet of Thinks) Based Smart Socket. International Journal of Engineering Trends and Technology, 55(2), 56-60. https://doi.org/10.14445/22315381/ijett-v55p212

Shao, T. Y., Kao, S. L., \& Su, C. M. Taiwan AIS CubeSat Tracking System for Marine Safety. In 2019 International Conference on Intelligent Computing and its Emerging Applications (ICEA) (pp. 70-73). IEEE.

Susanti, N., Ma, A., Iriani, D., Fudholi, A., Studi Fisika, P., Sains dan Teknologi, F., ... Keguruan dan Ilmu Pendidikan, F. (2020). Comparison of Rainfall Analysis of Jaxa Satellite Rainfall Data on Stations Data in Jambi, 15(1), 15-20. Retrieved from www.arpnjournals.com

Tapiador, F. J., Turk, F. J., Petersen, W., Hou, A. Y., García-Ortega, E., Machado, L. A. T., ... de Castro, M. (2012). Global precipitation measurement: Methods, datasets and applications. Atmospheric Research. https://doi.org/10.1016/j.atmosres.2011.10.021

Van Tonder, H. P. (2005). Improving Automatic Position Reporting System (APRS) Throughput and Reliability (Doctoral dissertation, Stellenbosch: University of Stellenbosch). 